\title{
1 Predicting tile drainage discharge using machine learning
}

\section{2 algorithms}

3 Saghar Khodadad Motarjemi ${ }^{1}$, Anders Bjørn Møller ${ }^{1}$, Finn Plauborg ${ }^{1}$ and Bo Vangsø Iversen $^{1}$

4

5

6

7

${ }^{1}$ Department of Agroecology, Aarhus University, Blichers Alle 20, 8830 Tjele, Denmark

Correspondence to: Saghar K. Motarjemi (sa.m@agro.au.dk)

\section{Abstract}

Drainage systems can significantly improve the water management in agricultural fields. However, they may transport contaminants originating from fertilizers and pesticides and threaten ecosystems. Determining the quantity of drainage water is an important factor for constructed wetlands and other drainage mitigation techniques. This study was carried out in Denmark where tile drainage systems are implemented in more than half of the agricultural fields. The first aim of the study was to predict the annual discharge of tile drainage systems using machine-learning methods, which have been highly popular in recent years. The second objective was to assess the importance of the parameters and their impact on the predictions. Data from 53 drainage stations distributed in different regions of Denmark were collected and used for the analysis. The covariates contained 35 parameters including the calculated percolation and geographic variables such as drainage probability, clay content in different depth intervals, and elevation, all extracted from existing national maps. Random Forest and Cubist were selected as predictive models. Both models were trained on the dataset and used to predict yearly drainage discharge. Results highlighted the importance of the cross-validation methods and indicated that both Random Forest and Cubist can perform as predictive models with a low complexity and good correlation between predicted and observed discharge. Covariate importance analysis showed that among all of the used predictors, the percolation and elevation have the largest effect on the prediction of tile drainage discharge. This work opens up for a better understanding of the dynamics of tile drainage discharge and proves that machine-learning techniques can perform as predictive models in this specific concept. The developed models can be used in regard to a national mapping of expected tile drain discharge.

Keywords: Tile drainage discharge, Random Forest, Cubist, Cross-validation

\section{Introduction}

Artificial subsurface drainage has a huge impact on the hydrology, nutrient cycling, and sediment dynamics in agricultural systems (Blann et al. 2009). In temperate climates with fine-textured soils as well as semi-arid regions with 
irrigated fields (Ayars et al. 2006), tile drainage is a crucial water management system to control runoff, prevent waterlogging, and to increase water use efficiency. On the other hand, tile drainage affects both the quantity and the quality of water resources (Schilling et al. 2012). Nutrient losses and chemical remnants can either be transported through drains to surface water bodies such as lakes and rivers (Stenberg et al. 2012) or be leached to the groundwater, and this fresh-water contamination can threaten both human and ecosystem health (Kuzmanovski et al. 2015).

Constructed wetlands are a means to eliminate excessive amounts of nitrogen from drainage water benefiting from natural nitrate reducing processes in a controlled environment (Messer et al. 2017). These systems are mainly installed to reduce the pollution from drainage water from agricultural fields and run-off from industrial areas (Magmedov et al. 1996). In order to design constructed wetlands with appropriate sizes, it is necessary to quantify artificial drainage discharge. Physically-based hydrological models have been developed either to estimate the drainage discharge or to include it as a component (De Schepper et al. 2017). These models have a common use in academic research and may as well be used to evaluate various scenarios (Zia et al. 2015). However, they depend on numerous parameters and require calibration to individual areas (Basha et al. 2008), which makes them complicated and time consuming to apply on a national scale. Another disadvantage of these models is the conceptualization as the fundament, which leads to invalid predictions when new empirical data are introduced (Bredehoeft 2005). Beside physically based models, many statistical approaches have been used to model and to predict state variable such as discharge, but there are limited number of literature predicting tile drainage discharge with the means of machine learning approaches. This type of data-driven modelling requires fewer parameters and can perform as an accurate estimation technique and these models have proved to be flexible and robust enough for many regression applications (Park et al., 2016).

Machine learning is related to computational statistics and is commonly used for predictions based on learning from historical relationships and trends in the data. Classification and Regression Trees (CART) are a frequently used form of machine learning models. They work by searching through the covariates of a dataset to find the best splitting single value. This creates two different groups of data. The process is repeated for the both created groups until a decision tree forms. Zia et al. (2015) predicted drainage discharge utilizing an M5 decision tree modelling technique on a 17 ha drained farmland in southern Ireland. Predictions were carried out on a daily basis for a 12-month period. They validated the suitability of a simplified discharge prediction model for implementation on a system with limited resources. Kuzmanovski et al. (2015) evaluated machine-learning models in predicting sub-surface tile drainage discharge and surface runoff on an experimental site in La Jaillière, France using daily data from eleven fields including a reference field. The dataset was based on meteorological measurements, agricultural practices, and crop management. By 
comparing the results from these models with the performance of two physically based models, they found an improvement in the sub-surface discharge predictions.

In the present study, two different machine-learning models were used to predict yearly tile drainage discharge, Random Forest (RF) (Breiman, 2001) and Cubist (CB) (Quinlan, 1993). RF is an ensemble approach based on CART (Breiman, 2001). It trains a number of regression trees from bootstrap samples drawn from the original dataset and averages the results from each tree for the final prediction. The algorithm furthermore introduces randomness into the splitting process by selecting the optimal split from a random subset of the covariates in each split. CB is a rule-based regression technique, which does not retrieve one final model like RF but a set of rules related to multivariate models (Walton, 2008). A specific set of covariates will choose an actual prediction model based on the rule that best fits the predictors. As a commercial and proprietary product, $\mathrm{CB}$ has the least algorithmic documentation comparing to random forest. However, Kuhn et al. (2013) ported it into R, which led to its popularity and it is currently being widely used as a regression method.

Both RF and CB have been used widely in the recent decades to predict different climatic or environmental parameters. However, there are few studies, which aim to compare RF and CB models. Walton (2008) estimated urban forest canopy cover and impervious surface cover using three different models including $\mathrm{CB}$ and RF and compared their performances. They concluded that CB was the best choice for predicting urban impervious surface cover. Noi et al. (2017) compared the results of Multiple Linear Regression, Cubist Regression, and Random Forest Algorithms in estimation of daily air surface temperature. They concluded that using different combinations of data, RF or CB algorithms resulted in high accuracies.

In this study, the chosen methodology is based on machine learning, which is considered as a promising modelling method in the fields of agriculture and environmental science (Debeljak and Dzeroski 2011). Here we aim to assess the performance of RF and CB in predicting yearly tile-drainage discharge, to compare the results achieved by both RF and $\mathrm{CB}$, and to analyze and rank the importance of the covariates.

\section{Materials and Methods}

\subsection{Study Area}

Denmark is located in northern Europe with a total area of $42,895 \mathrm{~km}^{2}$, of which $66 \%$ are used for agricultural purposes (Statistics Denmark, n.d.). The climate is temperate with an approximate mean annual precipitation (P) of $770 \mathrm{~mm}$ (Wong, 2013). The mean temperature is $7.7^{\circ} \mathrm{C}$ ranging from $1.5^{\circ} \mathrm{C}$ in January to $16.3^{\circ} \mathrm{C}$ in July. The mean elevation is $31 \mathrm{~m}$ above sea level and the landscape is generally flat. The geology divides Denmark into two main areas. An eastern 
part with loamy Weichselian moraines and a western part with sandy glacial outwash plains and Saalian moraines. According to historical maps, wetlands originally covered more than over $20 \%$ of the country but due to drainage activities, they have been reduced in extent during the $19^{\text {th }}$ and $20^{\text {th }}$ centuries.

\subsection{Data}

Data from 53 drainage stations in different locations and regions of Denmark were used in this study (Fig. 1). It included data from 18 stations established between 2012 and 2016 and historical data from 34 older stations established between 1971 and 2009, of which some are still running and some had been shut down (Hansen \& Pedersen 1975; Hansen 1981; Simmelsgaard 1994; Grant et al. 2009; Kjær et al. 2011; Kjærgaard et al. 2016). Some data originates from ongoing unpublished drain discharge stations, which have been established in relation to the monitoring of constructed miniwetlands. Other data belongs to a former project, iDræn (www.idraen.dk, 2011) where data for some of the stations have been published earlier (Hansen et al. 2018a,b; Varvaris et al. 2019a,b). For many stations, drainage discharge (Q) was measured on a daily basis but for some, Q was only measured on a weekly, monthly, or yearly basis. Based on the drain catchment area, yearly values were converted to a water height per year $\left(\mathrm{mm} \mathrm{y}^{-1}\right)$ based on the period from 1 July to the end of June to incorporate a full hydrological year. Most of the old stations had available data for a range of 19 to 23 years, whereas for some of the new stations there was only data for a few years ( 1 to 5 years). The lowest discharge $(0$ $\mathrm{mm} \mathrm{y}^{-1}$ ) was recorded in southeast Funen during the year 1995 - 1996, whereas the maximum discharge $\left(1183 \mathrm{~mm} \mathrm{y}^{-1}\right)$ was recorded in eastern Jutland during the year 2015 - 2016. The mean discharge for all the stations was $228 \mathrm{~mm} \mathrm{y}^{-1}$. The catchment sizes varied from 1 to 164 ha with a mean of 9 ha.

Thirty-seven different covariates were used as predictors (Table 1). Percolation out of the root zone (Db) was calculated with the simple water balance model EVACROP (Olesen and Heidmann, 1990) driven by input of daily precipitation (P) and reference evapotranspiration $\left(\mathrm{ET}_{0}\right)$. This was done since it was not expected that $\mathrm{P}$ during the growing season would contribute to $\mathrm{Q}$ due to the high ET during this period minimizing the percolation out of the root zone. However, the calculated $\mathrm{Db}$ is in general closely related to $\mathrm{P}$ and $\mathrm{Q}$ (Fig. 2). The average $\mathrm{Q}$ and the average $\mathrm{Db}$ were calculated for each station to determine the ratio between $\mathrm{Q}$ and $\mathrm{Db}$ (Fig 3). As shown in Figure 3, for seven stations out of 53, the tile drainage discharge is more than the percolated water. These stations are located in large catchments often in stream valleys where external sources (such as regional groundwater) probably flow to the tile drains from outside the catchment. The absolute amounts of discharged water in all the stations is normalized based on catchment area. 
Thirty-three out of 37 covariates were extracted from existing national maps. Topographical variables were calculated by (Møller et al. 2018) based on a digital elevation model (DEM, Fig. 4A) with a 30.4-meter grid size aggregated from a DEM with a 1.6-meter resolution. Adhikari et al. (2013) predicted maps of clay contents for the upper two meter of the soil at a resolution of $30.4 \mathrm{~m}$. These were aggregated by Møller et al. (2018) producing input data in form of maps of clay content in four depth intervals (Clay A\%, Clay B\%, Clay C\%, Clay D\%, Table 1, Fig. 4B). Values of clay content were also obtained from a national soil profile database using values from the nearest excavated soil profile. Depth to groundwater (Gwd_model, Table 1, Fig. 4C) was first calculated based on a model at a 500-meter resolution (Henriksen et al., 2012) and then the groundwater table was resampled to a 30.4-meter resolution using bilinear interpolation (Møller et al. 2018). Topographic Wetness Index (TWI, Table 1, Fig. 4D) that quantifies topographic controls of basic hydrological processes (Schillaci et al., 2015) was derived through interactions of fine-scale landform coupled to the upgradient contributing land surface area by Møller et al. (2018). A map of soil drainage classes (Møller et al., 2017), a rasterized choropleth map of geology (Jacobsen et al., 2015), and a map of wetland areas (Wetlands, Table 1, Greve et al. 2014) were also used in the analysis. Horizontal and vertical distances to surface waterbodies were included based on Møller et al. (2018), who calculated horizontal distances to waterbodies as the two-dimensional Euclidean distance to vector layers of waterbodies. Hereafter, they calculated the slope to channel as the angle to the hydrologically nearest waterbody taking into account the surface flow direction. Møller et al. (2018) predicted artificially drained areas (D_DK_New, Table 1) in Denmark by means of a selective model ensemble including number of geographic variables. All 37 covariates were used as input to the statistical models.

\subsection{Models and Measures of Accuracy}

As mentioned earlier, two machine-learning algorithms Cubist (CB) (Quinlan, 1993) and Random Forest (RF) (Breiman, 2001) were used to predict tile drainage discharge. Cross-validation was used to adjust the parameters of the models and to assess their predictive accuracy. Cross-validation is a resampling procedure used to evaluate machine-learning models on a given dataset. For $\mathrm{CB}$, the parameters were adjusted to committees and neighbors. The parameter committees sets the number of boosting iterations while the parameter neighbors set a number of nearby cases, which can be used for interpolation in order to adjust the predictions. For RF, the parameter mtry was adjusted, which sets the number of randomly selected covariates that are available in each split.

For both algorithms, three different cross-validation procedures were used. Firstly, in order to assess the ability of each model to predict the tile drain discharge at a new location, leave-station-out (LSO) cross-validation was performed. In this procedure, all the measurements were removed from one station in the data sample and a model was trained from the 

resulting accuracy was calculated.

The stations used in this study are highly clustered in geographic space (Fig. 1). Spatial autocorrelation may therefore affect the accuracy of the LSO procedure as stations may show similar patterns only because they are located close to each other. Therefore, a second cross validation procedure as leave-cluster-out was used as well, in which the clusters of stations were left out instead of individual stations. To achieve this, clusters were generated based on the distances between the stations. Stations located less than $10 \mathrm{~km}$ from each other were therefore grouped into clusters. This procedure resulted in 23 clusters with $1-10$ stations each. These clusters were later used for cross-validation.

Finally, k-fold cross-validated (KF) RF and CB models were trained on the whole dataset. In this procedure, the dataset were randomly divided into $\mathrm{k}$ disjoint folds, which are approximately equal in size. Each of the folds is used to test the generated model from the rest of k-1 folds. The performance of the algorithm was evaluated by the average of the resulting $\mathrm{k}$ accuracies from the cross-validation. When a specific value for $\mathrm{k}$ was chosen, it could be used in place of $\mathrm{k}$ in the reference to the model, which in this case $\mathrm{k}=10$ and it could therefore be referred as 10-fold cross-validation (Wong 2015).

In total, six models were trained as the CB and RF models were trained separately with leave-station-out (LSO), leavecluster-out (LCO), and $k$-fold (KF) cross validations. The accuracy of all five models were assessed with root mean square error (RMSE):

$R M S E=\sqrt{\frac{\sum_{i=1}^{n}\left(Q_{m_{i}}-Q_{o_{i}}\right)^{2}}{n}}$

where $\mathrm{Q}_{\mathrm{mi}}$ is the predicted value of yearly drainage discharge for the $i$-th instance, $\mathrm{Q}_{\mathrm{oi}}$ is the observed or measured value of yearly drainage discharge for the $i$-th instance, and $\mathrm{n}$ is the total number of instances.

The Nash-Sutcliffe efficiency (NSE) was used for validation as well:

$N S E=1-\frac{\sum_{i=1}^{n}\left(Q_{m_{i}}-Q_{o_{i}}\right)^{2}}{\sum_{i=1}^{n}\left(Q_{o_{i}}-\bar{Q}_{o}\right)^{2}}$

where $\bar{Q}_{o}$ is the mean of observed discharges.

Furthermore, to analyze the effect of the covariates in each model, the covariate importance was extracted from all six models. The covariate importance measures were scaled to $100 \%$ for the most important covariate in each model. In the beginning, all of the 37 parameters were introduced as covariates to the model. However, the purpose of using machine- 
learning is to find a simpler way to predict the target and to determine the most effective parameters, which helps to reduce the number of covariates and exclude the ineffective ones.

\section{Results and Discussion}

\subsection{Model accuracy}

The most accurate predictions were obtained by 10-Fold (KF) cross-validated Cubist (CB) and 10-Fold (KF) crossvalidated random forest (RF) with RMSE of 75 and $77 \mathrm{~mm} / \mathrm{y}$ and NSE of 0.73 and 0.74, respectively (Fig. 5, Table 2). According to Singh et al. (2005), an acceptable value for RMSE in hydrological modelling would normally be half of the standard deviation of training data, which for the current data set was $166(\mathrm{~mm} / \mathrm{y})$. Therefore, leave-station-out (LSO) cross-validated random forest (RF) with an RMSE of $110 \mathrm{~mm} / \mathrm{y}$ and LCO cross-validated CB with an RMSE of 113 $\mathrm{mm} / \mathrm{y}$ could be considered as acceptable models regarding the prediction of $\mathrm{Q}$.

The purpose of performing three different cross-validations was to test the model accuracy with and without the effect of geological biases. In LSO, a single station containing an entire data set is removed from the training dataset as the target of prediction. However, the model is still trained on the neighbor stations, which are regionally close to the target. That could cause overfitting issues. On the other hand, the LCO ensures that on each run of the model, one of the 23 clusters is excluded as the prediction target, which diminishes the possibility of overfitting caused by geo-regional similarities.

Finally, KF randomly divided the whole dataset into 10 fold with equal size, which does not consider the distribution of the stations. Data is sampled based on the rows and the difference in size between the training set used in each fold and the entire dataset is only a single pattern. Each fold contains 41 rows that are selected randomly and each time one of the 10 folds is the validation or test data set. The repeated cross-validation guarantees that different combinations of randomly selected stations are in different training folds limiting the possibility of overfitting.

With all three cross-validation methods, the accuracies with RF and $\mathrm{CB}$ were quite similar. Furthermore, the accuracies calculated with LSO and LCO are relatively similar, compared to KF, which had a substantially higher NSE and lower RMSE than the two other cross-validation methods.

\subsection{Covariate importance}

Results of all the six models indicate that the percolation or discharge out of the root zone ( $\mathrm{Db}$ ) has the largest effect on the tile-drainage discharge prediction with $100 \%$ importance (Fig. 6). The analyses show that elevation (DEM) follows the $\mathrm{Db}$ as the second most important covariate in all the models with more than $80 \%$ importance in LSO-CB and LCO-CB 
(Fig. $6 \mathrm{a}$ and b) and between approximately 40 to $50 \%$ effectiveness for the other four models (Fig. $6 \mathrm{c}$ to f). The clay content in the D horizon was the third most important covariate in KF-CB and KF-RF (Fig. 6c to f). For the LCO-CB and LSO-RF models, horizontal distance to the nearest waterbody appears as the third most important covariate with $45 \%$ and $21 \%$ importance, respectively (Fig. 6a and d). Whereas for the LSO-CB model, clay content in the C horizon and the LCORF model clay content in the B horizon where the third most important covariates (Fig. 6 b and c). The rest of the list differs between the different models. However, it is observable that for the RF models (Fig $6 \mathrm{c}$ to e) only the first covariates have a significant effect where the rest have less than $20 \%$ importance. Nevertheless, for all CB models (Fig $6 \mathrm{a}, \mathrm{b}$, and f) the top 10 covariate all have more than $20 \%$ importance. As previously stated, percolation and elevation have the largest importance to all of the trained models for the prediction of discharge. Based on the analyses of covariate importance, the results of the predictions for the two most effective covariates were compared to their measurements (Fig. 7). This comparison demonstrates how well the models can simulate the relationship between the most important covariates (Db and elevation) and the prediction target $(\mathrm{Q})$. The open black circles represent the predictors on the $\mathrm{x}$-axis against the measured drainage discharge $(\mathrm{Q})$ on the $\mathrm{y}$-axis. The red open circles represent the predictors on $\mathrm{x}$ axis and predicted drainage discharge $(\mathrm{Q})$ on the $\mathrm{y}$-axis by each of the six models mentioned on top of the plots. The best match could be observed on the k-fold cross-validated CB (Fig. 7 e and f).

\subsection{Discussion}

Similar studies targeting the prediction of discharge with machine learning models developed their models in a catchment scale for time series and chose the daily meteorological data, agricultural practices, and crop management as covariates (Kuzmanovski et al. 2015, Zia et al. 2015). Also in these studies, they used 10-fold cross-validation to evaluate the robustness of their model performance. The present study was carried out on a larger scale with catchments of different sizes distributed in different regions. Along with the percolation, a number of different geological features were used as input parameters to assess if it is possible to predict the tile drainage discharge based on spatially variable geophysical characteristics of the different sites. In the few similar studies (Rasouli et al. 2012, Kuzmanovski et al. 2015, Zia et al. 2015), the study area was either one specific catchment or few fields or catchments very close to each other. This means that the geological features were similar. Being able to train machine-learning models on different catchments in very different locations had enabled us to make use of differing geographical characteristics as predictor variables. Predictions were carried out in a yearly basis and were cross-validated with three different methods.

The accuracies of RF and CB models in comparison to each other for all the cross-validation methods were quite similar. On the other hand, the obtained accuracies from LSO and LCO are relatively similar but lower compared to KF, which 
had a substantially higher NSE and lower RMSE than the two other cross-validation methods. The higher accuracies achieved by KF is most likely results from having the observations of a given station from other years during the prediction procedure. The accuracy obtained with KF could be considered as the internal accuracy of the model, while LSO and LCO better represent the accuracies at new locations without previous measurements of tile drain discharge at the same station. The proposed tile-drainage discharge predictive model is not dependent on the climatic and constantly measured data and makes it possible to use different geographical properties as predictive parameters.

Logically, Db is the main driving variable since it takes into account water lost by evaporation from the soil surface, transpiration of water by the crop, and the increase of water stored in the soil. During the growing season, a high value of $\mathrm{P}$ will not necessarily lead to a corresponding high value of $\mathrm{Q}$ since it is only the part of $\mathrm{P}$ that infiltrate out of the root zone that potentially can flow into the tile drains. It is also expected that the clay content in the soil, especially the clay content in the lower horizons below tile drain depths, would have an effect on the drain discharge. A high clay content in the subsoil would lead to a secondary groundwater table building up outside the growing season to the level of the tile drains. That the clay content not play a more important role as a covariate might be explained by the relatively high prediction error of the clay content especially at lower depths for the used soil maps.

The position of the tile-drained field in the landscape will have an effect on the tile drain discharge. At low positions in the landscape, the flow of water to the drains is expected to be relatively high due to a high contributing area of expected incoming regional groundwater generated from a larger area outside the tile-drained field. Such areas are also indicated in Figure 3 corresponding to high values of $\mathrm{Q} / \mathrm{Db}$. On the other hand, at higher positions in the landscape with no or only a minor contribution of regional groundwater, a proportional part of the water infiltrating into the drains is generated mainly locally from water percolating out of the root zone (Db). It was expected that DEM derived indices such as TWI or SagaWI (Table 1) would describe more precisely the contribution of water in the tile drains and therefore supposed to be important covariates. Both indices attempt to describe the hydrological flow paths in the landscape and should be able to identify areas with a high contribution of water flowing to the drains. However, only for the k-fold cross-validated RF model (Fig. 6E), TWI is found within the list of the top 10 most import covariates. On the other hand, DEM is placed as the second most or the most important covariate for all models. This proves that the position in the landscape does have an effect on the tile drain discharge. That the derived topographical indices only play a minor role in the statistical models might be related to the fact that it can vary considerably within the individual drained catchments. On the other hand, other derived DEM indices such as valley depth (Valldepth), vertical distance to the nearest waterbody (Vdtochn), horizontal distance to the nearest waterbody (Hdtochn), and downhill gradient to the nearest waterbody (Slptochn) are all found in the top 10 list. 
By applying input from a distributed model predicting $\mathrm{Db}$ it is possible to apply the developed model on a national scale developing maps that can be used as a tool to predict the yearly drain discharge. National water resource models in Denmark exists that can be used for such purposes (e.g. Højberg et al. 2013). Outputs from the model can be based on averages for a certain period. Also, the possible variation between years as well as outputs in relation to future climatic scenarios can be studied.

\section{Conclusion}

For the current study, two different machine-learning models (RF and $\mathrm{CB}$ ) were applied on a relatively big dataset containing measured yearly drainage discharge $(\mathrm{Q})$ and 37 parameters as covariates and the results indicated a successful implementation. The predictive models were trained on 53 drainage stations distributed all over Denmark with different characteristics and multiple years of data and cross-validated with three different methods. The best results were achieved by k-fold (KF) cross-validated Cubist (CB) and random forest (RF) and the performance measures certifies the results. RMSE and NSE of both models indicates a good accuracy of the predictive models based on the hydrological modelling standards. Instead of physically-based models that acquire numerous parameters, machine learning models could perform as strong tools for quantifying the tile-drainage discharge with lower complexity. In this study, percolation or discharge out of the root zone $(\mathrm{Db})$ calculated with the simple water balance model EVACROP, and elevation (DEM) where the most important covariate for predicting yearly discharge. Finally, it was concluded that considering the distribution of stations, the method of sampling and the cross-validation has a large effect on estimates of model accuracies. The developed model can be used in relation to a national mapping of yearly tile drain discharge.

\section{Acknowledgments}

This study was supported partly by the Innovation Fund Denmark project Future Cropping (www.futurecropping.dk) and partly by the Ministry of Environment and Food of Denmark GUDP project iDræn (idraen.dk). We are grateful to David Nagy for his constant support and helpful comments.

\section{References}

Adhikari, K., R.B. Kheir, M.B. Greve, P.K. Bocher, B.P. Malone, B. Minasny, et al. 2013. High-Resolution 3-D Mapping of Soil Texture in Denmark. Soil Sci Soc Am J 77: 860-876. doi:10.2136/sssaj2012.0275.

Ayars, J.E., E.W. Christen and J.W. Hornbuckle. 2006. Controlled drainage for improved water management in and regions irrigated agriculture. Agr Water Manage 86: 128-139. doi:10.1016/j.agwat.2006.07.004. 
282

283

284

Basha, E.A., S. Ravela and D. Rus. 2008. Model-Based Monitoring for Early Warning Flood Detection. Sensys'08: Proceedings of the 6th Acm Conference on Embedded Networked Sensor Systems: 295-308.

Blann, K.L., J.L. Anderson, G.R. Sands and B. Vondracek. 2009. Effects of Agricultural Drainage on Aquatic Ecosystems: A Review. Crit Rev Env Sci Tec 39: 909-1001. doi:10.1080/10643380801977966.

Bredehoeft, J. 2005. The conceptualization model problem—surprise. Hydrogeology Journal 13: 37-46. doi:10.1007/s10040-004-0430-5.

Breiman, L. 2001. Random forests. Mach Learn 45: 5-32. doi:Doi 10.1023/A:1010933404324.

De Schepper, G., R. Therrien, J.C. Refsgaard, X. He, C. Kjaergaard and B.V. Iversen. 2017. Simulating seasonal variations of tile drainage discharge in an agricultural catchment. Water Resour Res 53: 3896-3920. doi:10.1002/2016wr020209.

Debeljak, M. and S. Dzeroski. 2011. Decision Trees in Ecological Modelling. Modelling Complex Ecological Dynamics: An Introduction into Ecological Modelling for Students, Teachers \& Scientists: 197-209. doi:10.1007/978-3-642-050299_14.

Grant, R., G. Blicher-Mathiesen, P.G. Jensen, B. Hansen, L. Thorling 2010. Landovervågningsoplande 2009. NOVANA. Danmarks Miljøundersøgelser, Aarhus Universitet. Faglig rapport fra DMU nr. 802. 124 pp. (https://www2.dmu.dk/Pub/FR802.pdf).

Greve, M.H., O.F. Christensen, M.B. Greve and R.B. Kheir. 2014. Change in Peat Coverage in Danish Cultivated Soils During the Past 35 Years. Soil Sci 179: 250-257. doi:10.1097/Ss.0000000000000066.

Hansen, A.L., R. Jakobsen, J.C. Refsgaard, A.L. Højberg, B.V. Iversen and C. Kjærgaard 2018a. Groundwater dynamics and effect of tile drainage on water flow across the redox interface in a Danish Weichsel till area. Advances in Water Resources 123:23-39.

Hansen, A.L., A. Storgaard, X. He, A.L. Højberg, J.C. Refsgaard, B.V. Iversen, C. Kjærgaard 2018b. Importance of geological information for assessing drain flow in a Danish till landscape, Hydrological Processes 33:450-462.

Hansen, B. 1981. Drænvandskvantitet og -kvalitet i Susåens opland. Suså-projekt. Dansk Komite for Hydrologi, Rapport Nr. Suså H 19. København, Denmark. 67 pp. (https://soeg.kb.dk/permalink/45KBDK_KGL/fbp0ps/alma99122878363105763) 
Hansen, L.; E.F. Pedersen 1975. Drænvandsundersøgelser 1971-74. Tidsskr. Planteavl 79 (670-688). (http://agris.fao.org/agris-search/search.do?recordID=US201303003414)

Henriksen, H.J., Højberg, A.L., Olsen, M., Seaby, L.P., van der Keur, P., Stisen, S., Troldborg, L., Sonnenborg, T.O., Refsgaard, J.C., 2012. Klimaeffekter på hydrologi og grundvand - Klimagrundvandskort. Aarhus University. (https://www.klimatilpasning.dk/media/340310/klimagrundvandskort.pdf)

Jakobsen, P.R., Hermansen, B., Tougaard, L., 2015. Danmarks digitale jordartskort 1:25000 version 4.0. GEUS. (http://pubs.geus.net/Danmark/jordartskort/Jordart 25000 beskriv.pdf)

Kjær, J., A.E. Rosenbom, W. Brüsch, R.K. Juhler, L. Gudmundsson, F. Plauborg, R. Grant, P. Olsen 2011. The Danish Pesticide Leaching Assessment Programme - Monitoring results May 1999-June 2010. Geological Survey of Denmark and Greenland and Aarhus University. Copenhagen, Denmark. 110 pp. (http://pesticidvarsling.dk/xpdf/vap-results-9910.pdf)

Kjærgaard, C.; Iversen, B.V.; Højberg, A.L.; Mathiesen, G.B. 2016. Drænmålinger som grundlag for emissionsbaseret kvælstofregulering. In Hvid, S.K. Måling af kvælstofudledning emmisionsbaseret kvælstofregulering på bedriftsniveau. SEGES, Aarhus, Denmark. Delrapport C. 67 pp. (https://www.landbrugsinfo.dk/Afrapportering/planter og miljoe/2016/Sider/pl_po 9993682 b3 Delrapport C Maali nger_i_draenra.pdf?download=true)

Kuhn, M., 2008. Building predictive models in R using the caret package. J. Stat. Softw. 28 (5), 1-26.

Kuzmanovski, V., A. Trajanov, F. Leprince, S. Dzeroski and M. Debeljak. 2015. Modeling water outflow from tiledrained agricultural fields. Sci Total Environ 505: 390-401. doi:10.1016/j.scitotenv.2014.10.009.

Magmedov, V.G., M.A. Zakharchenko, L.I. Yakovleva and M.E. Ince. 1996. The use of constructed wetlands for the treatment of run-off and drainage waters: The UK and Ukraine experience. Water Sci Technol 33: 315-323. doi:Doi 10.1016/0273-1223(96)00247-8.

Messer, T.L., M.R. Burchell, F. Birgand, S.W. Broome and G. Chescheir. 2017. Nitrate removal potential of restored wetlands loaded with agricultural drainage water: A mesocosm scale experimental approach. Ecol Eng 106: 541-554. doi:10.1016/j.ecoleng.2017.06.022.

Møller, A.B., A. Beucher, B.V. Iversen and M.H. Greve. 2018. Predicting artificially drained areas by means of a selective model ensemble. Geoderma 320: 30-42. doi:10.1016/j.geoderma.2018.01.018. 
Møller, A.B., Beucher, A., Iversen, B.V., Greve, M.H., 2017. Prediction of soil drainage classes in Denmark by means of decision tree classification. Geoderma. http://dx.doi.org/10.1016/j.geoderma.2017.10.015.

Noi, P.T., J. Degener and M. Kappas. 2017. Comparison of Multiple Linear Regression, Cubist Regression, and Random Forest Algorithms to Estimate Daily Air Surface Temperature from Dynamic Combinations of MODIS LST Data. Remote Sens-Basel 9. doi:ARTN 398 10.3390/rs9050398.

Olesen, J.E., Heidmann, T., 1990. EVACROP. Et program til beregning af aktuel fordampning og afstrømning fra rodzonen. Version 1.01. AJMET Arbejdsnotat 9, Statens Planteavlsforsøg. (https://docplayer.dk/storage/26/8897995/1577277319/r5LW4nhUDA12pzTOA7v1PA/8897995.pdf)

Park, S., J. Im, E. Jang and J. Rhee. 2016. Drought assessment and monitoring through blending of multi-sensor indices using machine learning approaches for different climate regions. Agr Forest Meteorol 216: 157-169. doi:10.1016/j.agrformet.2015.10.011.

Rasouli, K., Hsieh, W.W., Cannon, A.J., 2012. Daily streamflow forecasting by machinelearning methods with weather and climate inputs. J. Hydrol. 414, 284-293.

Schillaci, C., A. Braun, and J. Kropacek. 2015. Terrain analysis and landform recognition; Chapter 2.4.2, in Geomorphological Techniques; British Society for Geomorphology. 18 pp. Schilling, K.E., P. Jindal, N.B. Basu and M.J. Helmers. 2012. Impact of artificial subsurface drainage on groundwater travel times and baseflow discharge in an agricultural watershed, Iowa (USA). Hydrol Process 26: 3092-3100. doi:10.1002/hyp.8337. Simmelsgaard, S.E. 1994. Nitratkvælstof i drænvand 1971-91. Statens Planteavlsforsøg, SP-rapport nr. 47. Statens Planteavlsforsøg, Lyngby, Denmark. 67 pp. (https://soeg.kb.dk/permalink/45KBDK KGL/13io73r/faoagrisUS201300291267) Singh, J., H.V. Knapp, J.G. Arnold and M. Demissie. 2005. Hydrological modeling of the iroquois river watershed using HSPF and SWAT. J Am Water Resour As 41: 343-360. doi:DOI 10.1111/j.1752-1688.2005.tb03740.x.

Stenberg, M., B. Ulen, M. Soderstrom, B. Roland, K. Delin and C.A. Helander. 2012. Tile drain losses of nitrogen and phosphorus from fields under integrated and organic crop rotations. A four-year study on a clay soil in southwest Sweden. Sci Total Environ 434: 79-89. doi:10.1016/j.scitotenv.2011.12.039. 
https://doi.org/10.5194/hess-2019-650

Preprint. Discussion started: 2 January 2020

(C) Author(s) 2020. CC BY 4.0 License.

361 Varvaris, I., C.D. Børgesen, C. Kjærgaard, B.V. Iversen 2019a. Three two-dimensional approaches for simulating the water flow dynamics in a heterogeneous tile-drained agricultural field in Denmark. Soil Science Society of American Journal 82:1367-1383.

364

365
Varvaris, I, P. Moldrup, Z. Pittaki-Chrysodonta, L. W. de Jonge, and B.V. Iversen 2019b. Coupling vis-NIR and pedotransfer functions for predicting hydraulic properties to simulate water flow dynamics in a tile-drained agricultural field. Vadose Zone Journal (accepted).

Walton, J.T. 2008. Subpixel urban land cover estimation: Comparing Cubist, Random Forests, and support vector regression. Photogramm Eng Rem S 74: 1213-1222. doi:Doi 10.14358/Pers.74.10.1213.

Wong, T.T. 2015. Performance evaluation of classification algorithms by k-fold and leave-one-out cross validation.

Pattern Recogn 48: 2839-2846. doi:10.1016/j.patcog.2015.03.009.

Zia, H., N. Harris, G. Merrett and M. Rivers. 2015. Predicting discharge using a low complexity machine learning model.

Comput Electron Agr 118: 350-360. doi:10.1016/j.compag.2015.09.012. 


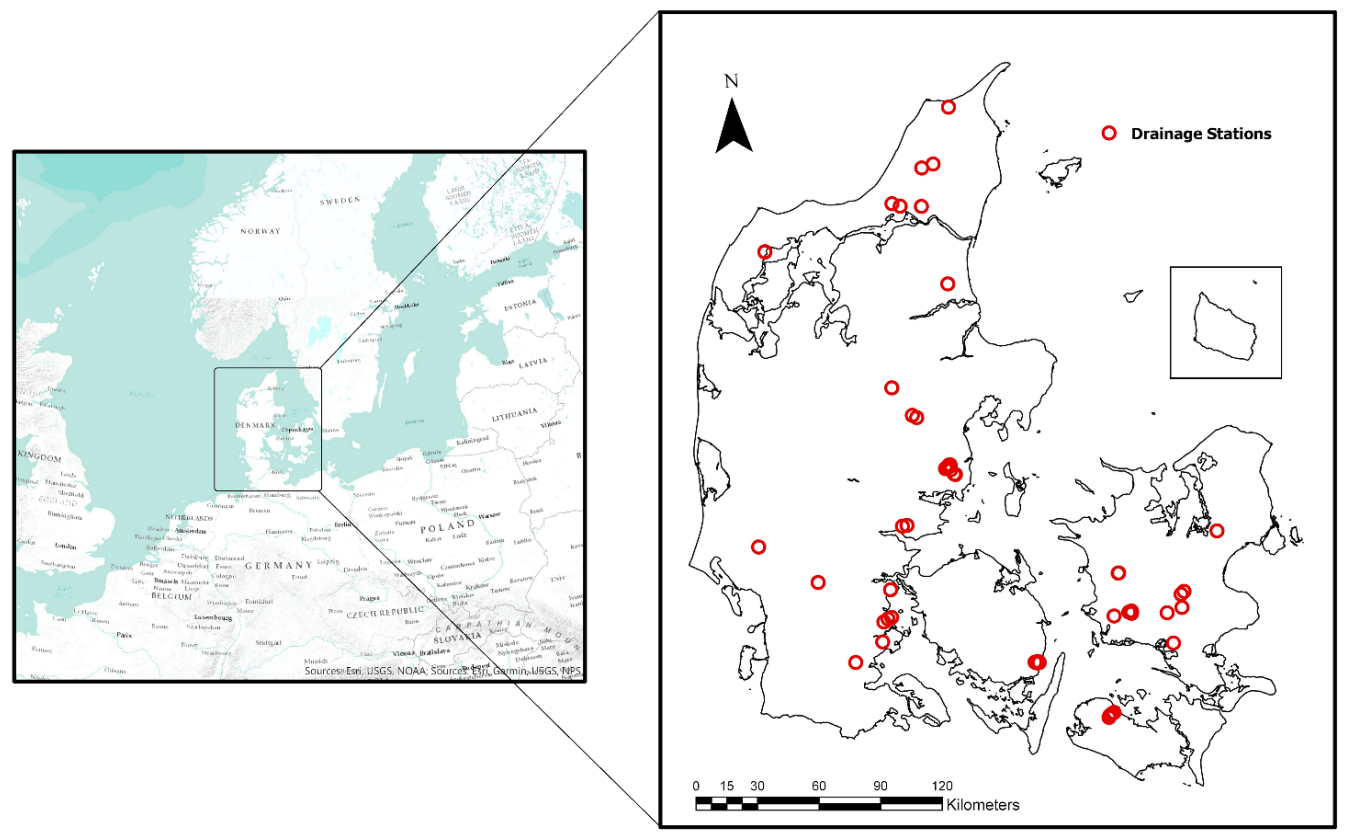

Figure 1. Study area and the location of the 53 drainage stations throughout Denmark
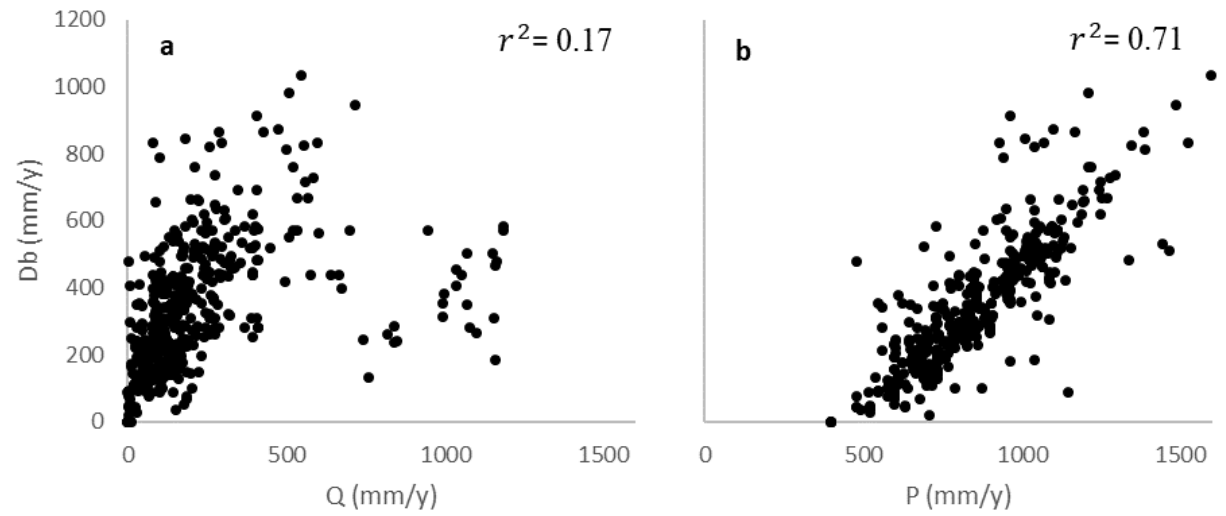

Figure 2. a) Measured yearly drainage discharge (Q) against calculated percolation (Db) b) Observed precipitation (P) against calculated percolation (Db) 
https://doi.org/10.5194/hess-2019-650

Hydrology and

Preprint. Discussion started: 2 January 2020

(c) Author(s) 2020. CC BY 4.0 License.

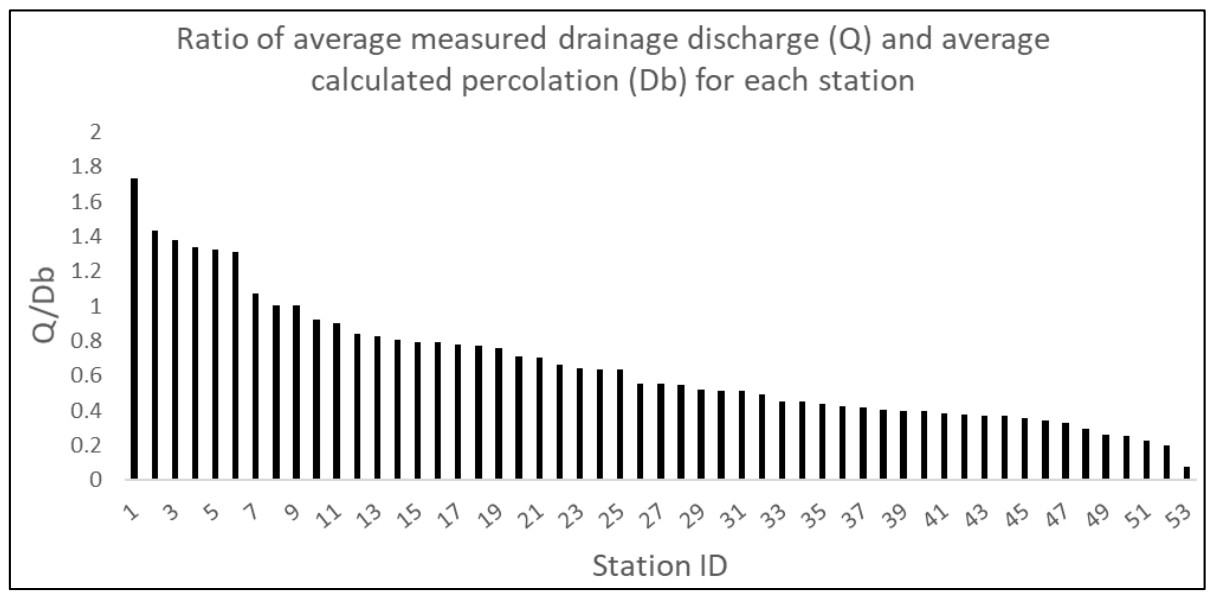

Figure 3. Ratio of average measured drainage discharge (Q) and average calculated percolation (Db) for each station 

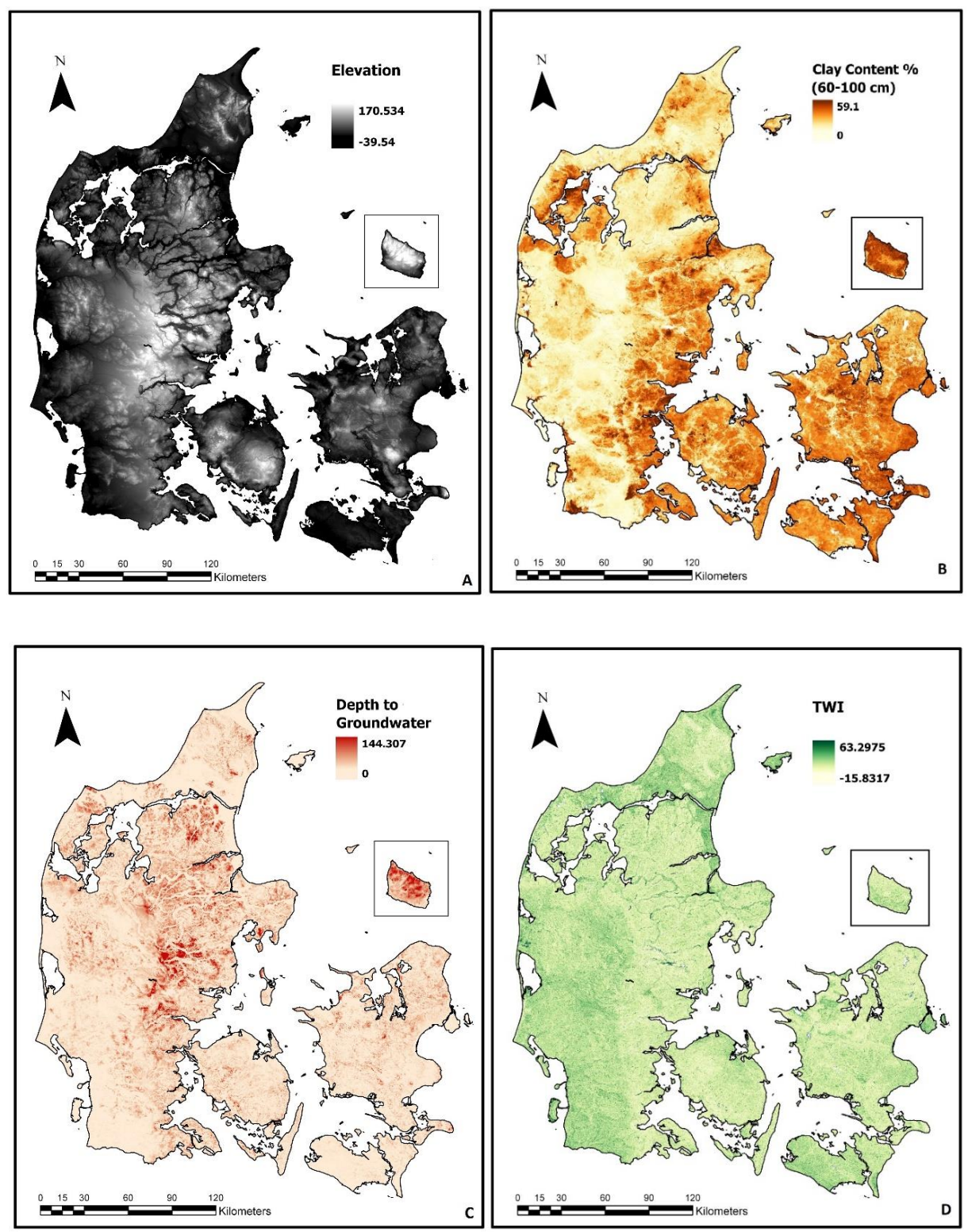

Figure 4. A. Elevation based on a Digital Elevation Map (DEM). B. Aggregated clay content in the C-horizon (Møller et al., 
https://doi.org/10.5194/hess-2019-650

Preprint. Discussion started: 2 January 2020

(c) Author(s) 2020. CC BY 4.0 License.
Hydrology and

Discussions
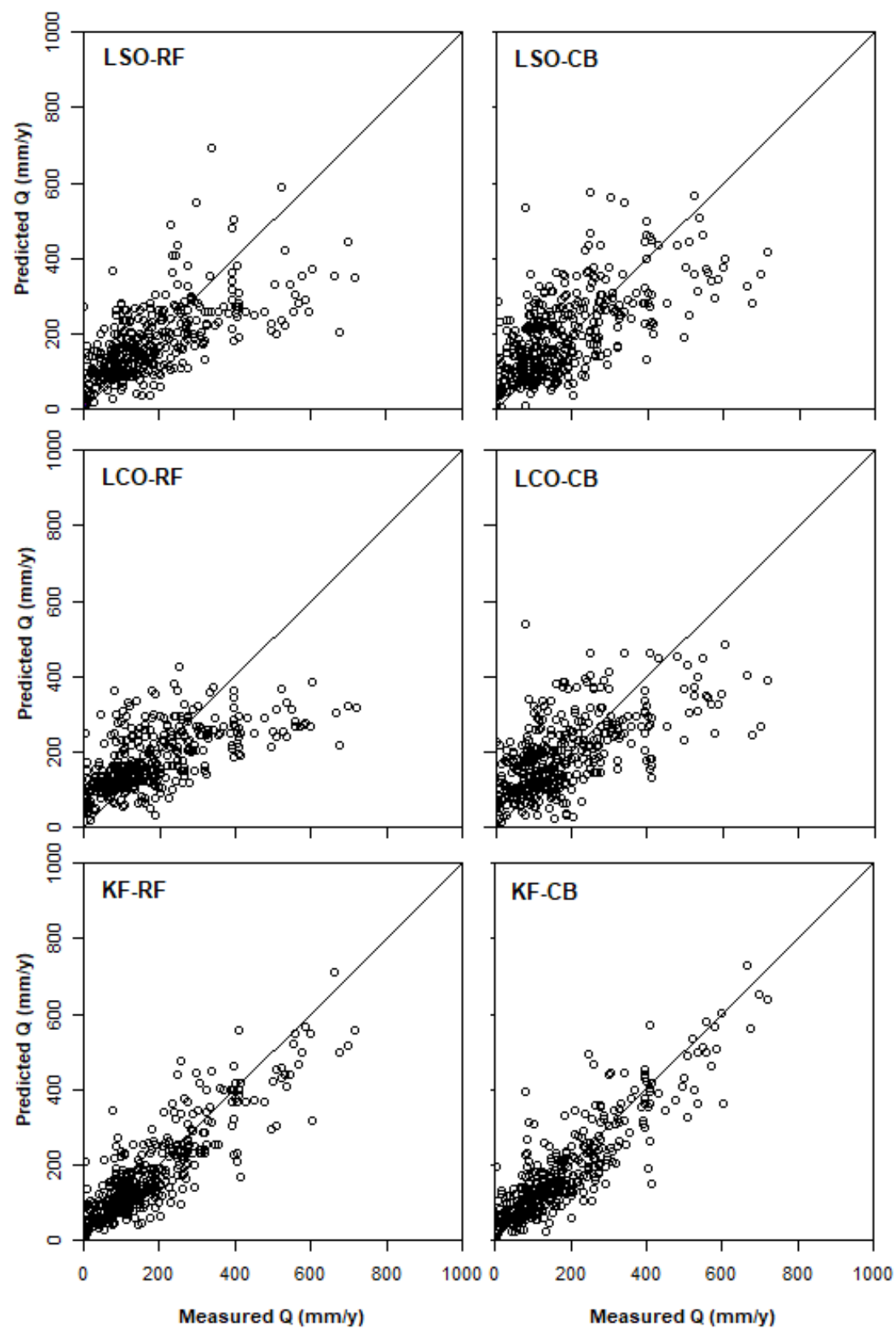

389

Figure 5. LSO-RF: Leave station out cross-validated random forest model. LSO-CB: Leave station out cross-validated cubist

model. LCO-RF: Leave cluster out cross-validated random forest model. LCO-RF: Leave cluster out cross-validated cubist model. KF-RF: K-Fold cross-validated random forest model. KF-CB: k-fold cross-validated Cubist model. 
https://doi.org/10.5194/hess-2019-650

Preprint. Discussion started: 2 January 2020

(c) Author(s) 2020. CC BY 4.0 License.
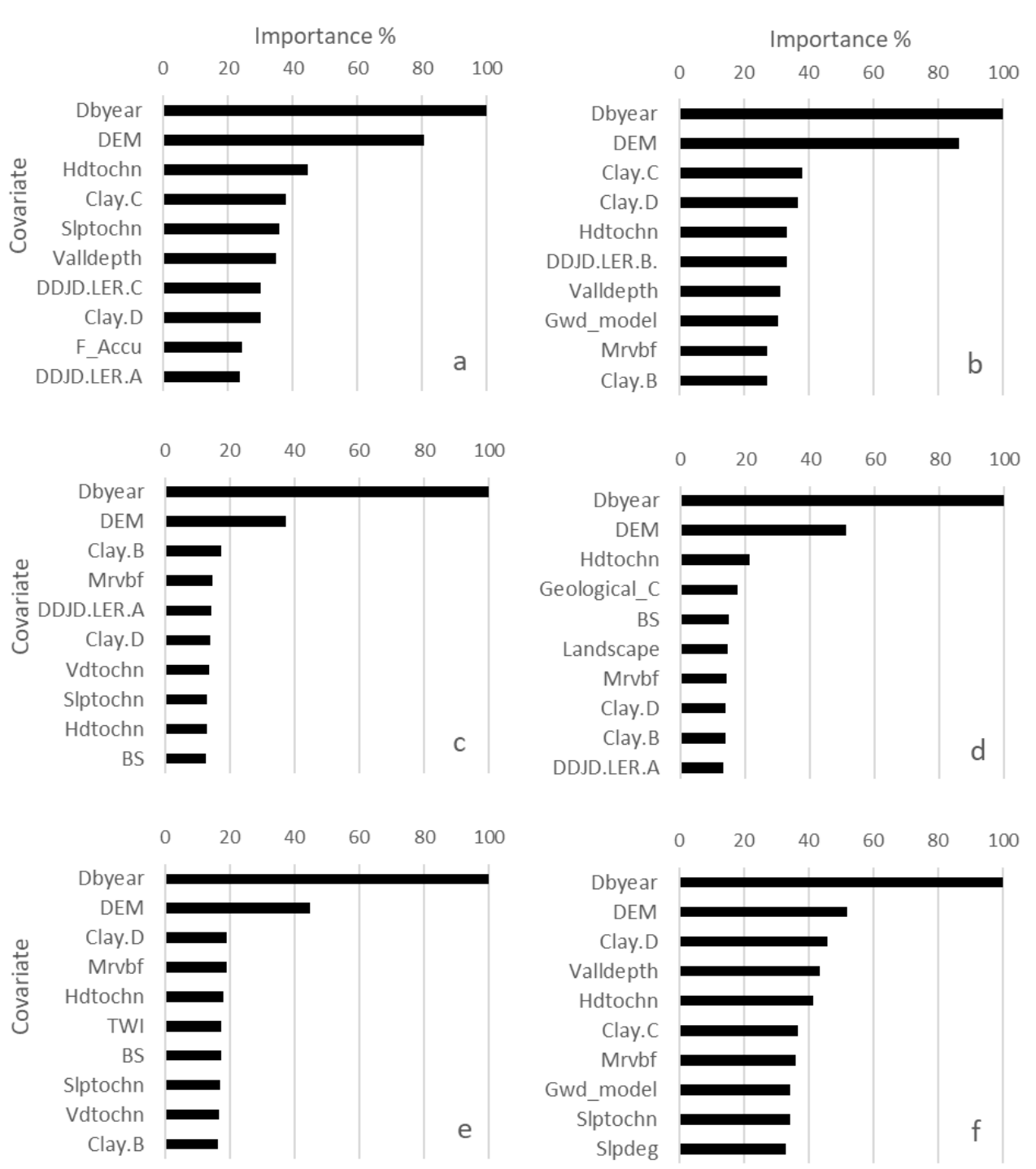

Figure 6. a) Top 10 most important covariates of the leave-cluster-out cross-validated CB model b) Top 10 most important covariates of the leave-station-out cross-validated CB model c) Top 10 most important covariates of the leave-cluster-out crossvalidated RF model d) Top 10 most important covariates of the leave-station-out cross-validated RF model E) Top 10 most model. 

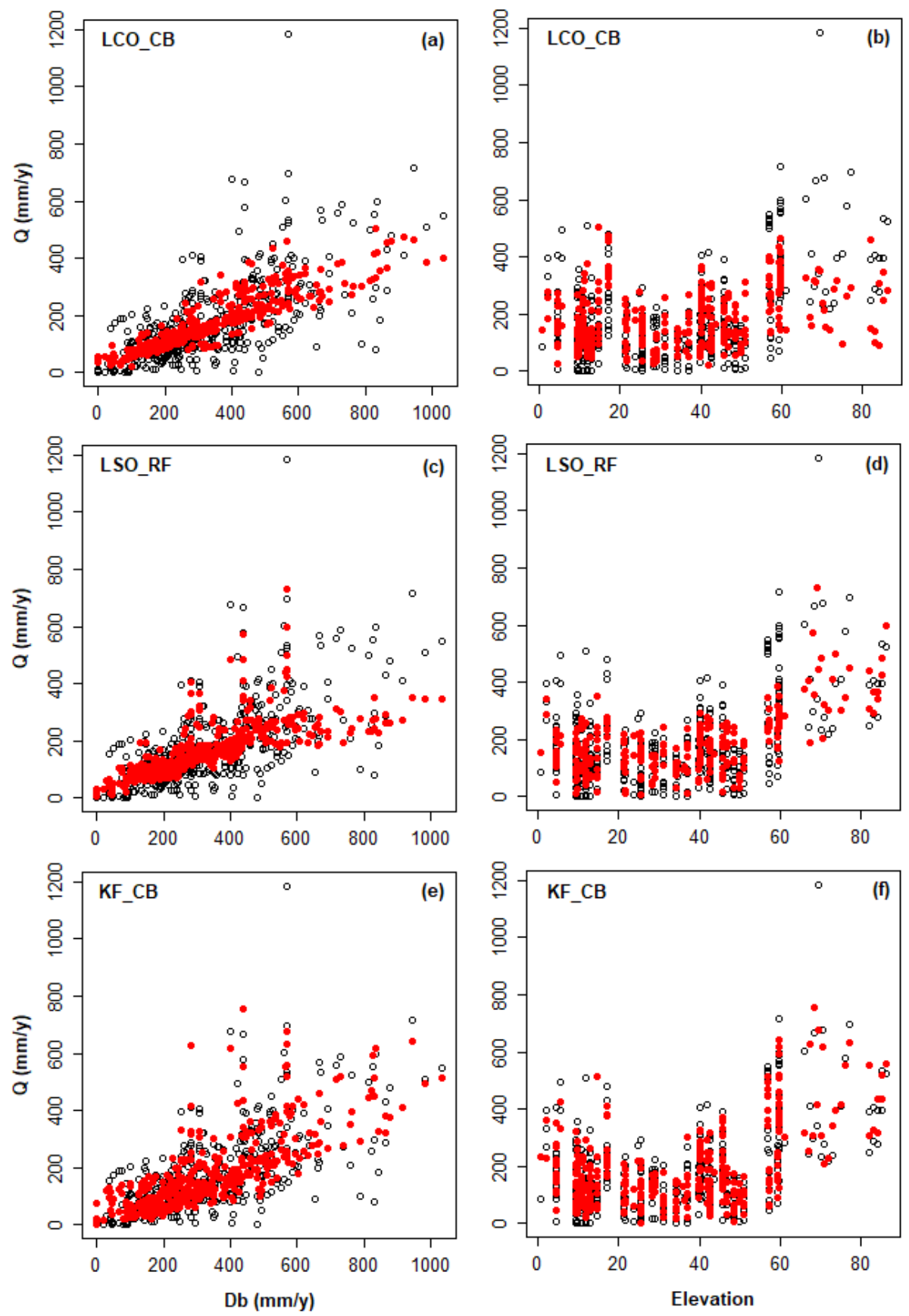
https://doi.org/10.5194/hess-2019-650

Preprint. Discussion started: 2 January 2020

(c) Author(s) 2020. CC BY 4.0 License.

401 elevation in black open circles, predicted discharge against elevation in red open circles for selected models with the best

Table 1. List of covariates used to predict the discharge including a description of the parameter and a range specifying the type of covariate.

\begin{tabular}{|c|c|c|}
\hline Predictors & Description & Range/ Class \\
\hline $\mathrm{Db}$ & $\begin{array}{l}\text { Percolation/Discharge out of the root zone (mm } \\
\left.\mathrm{y}^{-1}\right)\end{array}$ & $0-1033$ \\
\hline Geological_R & Geological region & 7 classes \\
\hline DEM & Elevation (m) & $0.74-83.16$ \\
\hline Geological_C & Geology of the area & 10 classes \\
\hline F_Accu & Flow Accumulation/Number of unslope cells & $1-1108$ \\
\hline SagaWI & SAGA Wetness Index & $12.16-16.58$ \\
\hline TWI & Topographic Wetness Index & $3.47-12.33$ \\
\hline BS & Depth of Sink (m) & $0-2.17$ \\
\hline D_Class & Drainage class & 5 classes \\
\hline Clay A \%† & Clay content $0-30 \mathrm{~cm}$ soil depth & $3-20.3$ \\
\hline Clay B \% $\dagger$ & Clay content $30-60 \mathrm{~cm}$ soil depth & $2-29.1$ \\
\hline Clay C \%† & Clay content $60-100 \mathrm{~cm}$ soil depth & $1.5-31$ \\
\hline Clay D \%† & Clay content $100-200 \mathrm{~cm}$ soil depth & $2.2-32.6$ \\
\hline DDJD LER-A\% $\%$ & Clay content in A horizon & $3-24.8$ \\
\hline DDJD LER-B $\% \ddagger$ & Clay content in B horizon & $0-31.97$ \\
\hline DDJD LER-C $\% \ddagger$ & Clay content in $\mathrm{C}$ horizon & $0-29.1$ \\
\hline JB & Danish soil classification for the A horizon & 12 classes \\
\hline Gwd_Int & $\begin{array}{l}\text { Depth to groundwater table interpolated from } \\
\text { well observations and surface water }(\mathrm{m})\end{array}$ & $0-25.31$ \\
\hline Wetlands & $\begin{array}{l}\text { 0: Non-wetlands; } 1: \text { Wetlands; } 2 \text { : Central } \\
\text { wetlands; } 3 \text { : Peatlands. }\end{array}$ & 4 classes \\
\hline D_DK_New & Artifical drainage-new map & 2 classes \\
\hline DP_New & Drainage probability-new map & $0-0.86$ \\
\hline
\end{tabular}




\begin{tabular}{llr}
\hline D_DK & Artifcial drainage-old map & 2 classes \\
DP & Drainage probability-old map & $0-0.82$ \\
Demdetrend & Elevation minus the mean elevation in a 4 km & $-11.4-26.04$ \\
& radius (m) & $1150.08-$ \\
Dirinsola & Direct insolation (kWh/year) & 1348.61 \\
& & $0-32.42$ \\
Gwd_model & Depth to groundwater from the model (m) & $0-1114.89$ \\
Hdtochn & Horizontal distance to the nearest waterbody (m) \\
Midslppos & Mid-slope position & $0-0.7$ \\
Mrvbf & Multi-resolution index of valley bottom flatness & $0.07-8.68$ \\
Slpdeg & Surface slope gradient (degrees) & $0.09-7.53$ \\
Slptochn & Downhill gradient to the nearest waterbody (m) & $0-3.48$ \\
Vdtochn & Vertical distance to the nearest waterbody (m) & $0-19.28$ \\
Valldepth & Valley depth (m) & $2.43-21.35$ \\
Landscape & Landform types & 11 classes \\
\hline of Adhikari et al. (2013); $\$$ from the national soil database &
\end{tabular}

Table 2. Error summary of six trained models

\begin{tabular}{|c|c|c|c|c|c|c|}
\hline Error & & & & & \\
\hline RSO-CB & LCO-CB & LSO-RF & LCO-RF & KF-RF & KF-CB \\
\hline NSE & 116.53 & 115.04 & 110.65 & 115.82 & 76.05 & 70.98 \\
\hline & 0.37 & 0.39 & 0.44 & 0.38 & 0.73 & 0.74 \\
\hline
\end{tabular}

407 